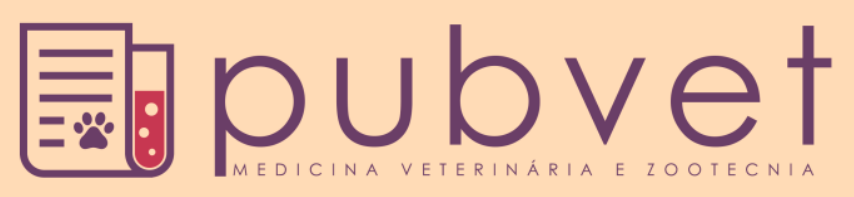

HTTP://DX.DOI.ORG/10.22256/PUBVET.V11N9.864-876

\title{
Diagnosticando a cistite idiopática felina: Revisão
}

\section{Murilo Ramos Bastos de Oliveira ${ }^{1 *}$, Catarina Rafaela Alves da Silva ${ }^{1}$, Kennya Cristina Damasceno de Jesus ${ }^{1}$, Karoline Figueredo Rodrigues ${ }^{1}$, Raquel Albuquerque Silva ${ }^{1}$, Sergio Diego Passos Costa ${ }^{1}$, Francisco Lima Silva ${ }^{2}$, Marcelo Campos Rodrigues ${ }^{2}$}

${ }^{I}$ Residente da Universidade Federal do Piauí, Departamento de Medicina Veterinária. Teresina, Piauí, Brasil.

${ }^{2}$ Professor da Universidade Federal do Piauí, Departamento de Medicina Veterinária. Teresina, Piauí, Brasil.

*Autor para correspondência, E-mail: murilorbo@hotmail.com

\begin{abstract}
RESUMO. Sabe-se que a casuística de gatos que apresentam sinais clínicos referentes ao trato urinário inferior (STUI) no mundo inteiro é enorme. Mas, reconhece-se também que, na maioria desses casos, não se conhece a causa específica que desencadeia tais sinais, assim como, sinais referentes a outros sistemas que por ventura venham a ser acometidos anteriormente ou concomitantemente aos STUI. O objetivo desse trabalho é investigar quais as evidências existentes atualmente sobre a cistite idiopática/intersticial felina (CIF) e como que se dá a abordagem do paciente felino para essa síndrome: quais perguntas devem ser feitas ao tutor, os achados dos exames físico e complementar, bem como os tratamentos mais indicados em cada caso em particular.
\end{abstract}

Palavras chave: hematúria, gato, polaquiúria síndrome, stui

\section{Diagnosing feline idiopathic cystitis: Review}

ABSTRACT. It is know that the casuistic of cats that present clinical signs referring to the lower urinary tract (STUI) worldwide is enormous. However it is also recognized that, in most of these cases, the specific cause that triggers such signals is not known, as well as signals referring to other systems that may be previously or simultaneously concomitant with STUI. The objective of this work is to investigate the current evidence on feline idiopathic / interstitial cystitis (CIF) and how to approach the feline patient for this syndrome: what questions should be asked to the tutor, the findings of the physical and complementary exams, as well as the treatments most indicated in each particular case.

Keywords: hematuria, cat, polaquiuria, syndrome, luts

\section{Diagnosticando la cistitis idiopática felina: Revisión}

RESUMEN. Se sabe que la casuística de gatos que presentan signos clínicos referentes al tracto urinario inferior (STUI) en el mundo es enorme. Pero se reconoce también que, en la mayoría de estos casos, no se conoce la causa específica que desencadena tales señales, así como, señales referentes a otros sistemas que por ventura se ven afectadas anteriormente o concomitantemente con los STUI. El objetivo de este trabajo es investigar cuáles son las evidencias existentes actualmente sobre la cistitis idiopática / intersticial felina (CIF) y cómo se da el abordaje del paciente felino para ese síndrome: qué preguntas deben ser hechas al tutor, los hallazgos de los exámenes físicos y complementário, así como los tratamientos más indicados en cada caso en particular.

Palabras clave: Hematuria, gato, polaquiuria, síndrome, stui 


\section{Introdução}

A denominação de Cistite Idiopática Felina ou Intersticial Felina (CIF) tem por base o significado de cistite, uma vez que se desenvolve com inflamação intersticial da bexiga, e o de idiopática (palavra derivada do grego idios, de si próprio, e pathos, sofrimento), por não ser conhecida a sua etiologia (Nunes, 2015). O termo Cistite Intersticial foi originalmente usado para descrever uma síndrome vesical álgica em humanos que é muito similar à CIF sendo, no humano, reconhecida como uma condição crônica, já no felino, como aguda ou crônica (Chew et al., 2012b).

Para gatos que manifestem sinais clínicos crônicos além dos sinais do trato urinário inferior (STUI), particularmente a nível endócrino, dermatológico, gastrintestinal, respiratório, cardiovascular e nervoso que, simultaneamente, não se identifica uma causa específica foi proposta a denominação Síndrome de Pandora (Buffington et al., 2014). Segundo Buffington (2011), essa última faz uma analogia à mitologia grega da Caixa de Pandora. A lenda conta que os deuses criaram Pandora, a primeira mulher, e deram-lhe uma caixa com presentes à qual nunca deveria abri-la. Mas, certo dia, a curiosidade venceu Pandora, fazendo-lhe abrir a caixa, liberando males como tristeza, doenças e epidemias no mundo. Ao perceber o problema que tinha desencadeado, Pandora fechou rapidamente a caixa, deixando presa a ela uma única coisa: esperança.

\section{Fisiopatologia}

Verifica-se que gatos acometidos por CIF apresentam alterações na bexiga, sistema nervoso e no eixo hipotalâmico-hipofisário-adrenal (HHA), mas sua fisiopatologia não é completamente conhecida (Tabar Rodrígues and Planellas Bachs, 2012). Em humanos existem duas formas histológicas de cistite intersticial, a não ulcerativa (tipo I) e ulcerativa (tipo II), ambas podem estar presentes também no gato e, assim como no humano, a tipo I é a mais relatada. A forma ulcerativa é evidenciada pela presença das chamadas úlceras de Hunner (Dibartola, 2015). O tipo II parece ser mais inflamatório, enquanto o tipo I pode estar associado às anormalidades neuroendócrinas, sugerindo que a inflamação pode ocorrer "em resposta a" em vez de ser "uma causa de" dano ao urotélio da bexiga (Keay et al., 2014). Foi demonstrado em pesquisa na bexiga de gatos com CIF crônica, que alterações histológicas são geralmente inespecíficas e podem incluir um urotélio intacto ou danificado com edema submucoso, dilatação de vasos sanguíneos submucosos com neutrófilos marginais, hemorragia submucosa e, por vezes, aumento da densidade de mastócitos (Buffington et al., 1997). Segundo Westropp (2011), além da inespecificidade dessas alterações, não existe correlação entre lesões histológicas (e mesmo cistoscópicas) e sinais clínicos em gatos.

Hipoteticamente, a vasodilatação e o subsequente extravasamento de proteínas plasmáticas dos capilares do plexo suburotelial e uretrite secundária, podem aprisionar cristais e outros debris no lúmen da uretra de gatos machos, resultando em obstrução uretral (OU) (Dibartola, 2015). Os cristais normalmente presentes no plug são de estruvita, pois à medida que o plasma é exsudado para a urina, o $\mathrm{pH}$ aumenta, favorecendo sua precipitação (Chew et al., 2012b).

Gatos diagnosticados com CIF apresentam alterações na ultraestrutura urotelial e proteínas de junções estreitas (Lavelle et al., 2000) (Figura 1). Em humanos, estudos têm avaliado alterações na expressão gênica e diferenciação urotelial (Slobodov et al., 2004, Hauser et al., 2008). Defeitos na diferenciação e proliferação das células epiteliais superficiais foram associados à presença do fator antiproliferativo, de modo que, diante de uma lesão, os mecanismos normais de substituição das camadas lesionadas por novas células epiteliais estariam comprometidos (Tabar Rodrígues and Planellas Bachs, 2012). No estudo conduzido por Lavelle et al. (2000), um urotelio desnudado com aparência de células subjacentes foi encontrado por microscopia eletrônica de varredura e transmissão. Em outro artigo relatou achados de microscopia eletrônica surpreendentemente semelhantes em camundongos fêmeas saudáveis expostos a iluminação constante por 96 horas e, posteriormente, devolvidos à iluminação convencional dia-noite por 7 dias antes de serem eutanasiados. Esse estudo mostrou que lesões uroteliais comparáveis também podem ocorrer em animais saudáveis expostos a eventos externos estressantes (Veranic and Jezernic, 2000).

Foi relatado que gatos com CIF excretam quantidades diminuídas tanto de glicosaminoglicano (GAG) urinário total (Buffington et al., 1996) como de um GAG específico (GP-51) (Press et al., 1995), devido à 
redução da síntese, adesão dos GAGs às células uroepiteliais danificadas em alguns estudos (Chew et al., 2012b) e reabsorção pelo urotélio mais permeável. GAG e GP-51 contribuem para o muco de superfície que cobre o urotélio e acredita-se que inibam a adesão bacteriana (Tabar Rodrígues and Planellas Bachs, 2012). Pereira et al., (2004) encontraram sulfato de condroitina no plasma de gatos com síndrome urológica felina (SUF), levando-os a concluir que a diminuição da concentração de condroitina encontrada na urina poderia resultar da eabsorção por um urotelio mais permeável. Essas alterações na barreira urotelial também podem permitir que a água, a ureia e as substâncias nocivas presentes na urina passem para o tecido subjacente (camadas neurais e outras), resultando em STUI (Keay et al., 2014).

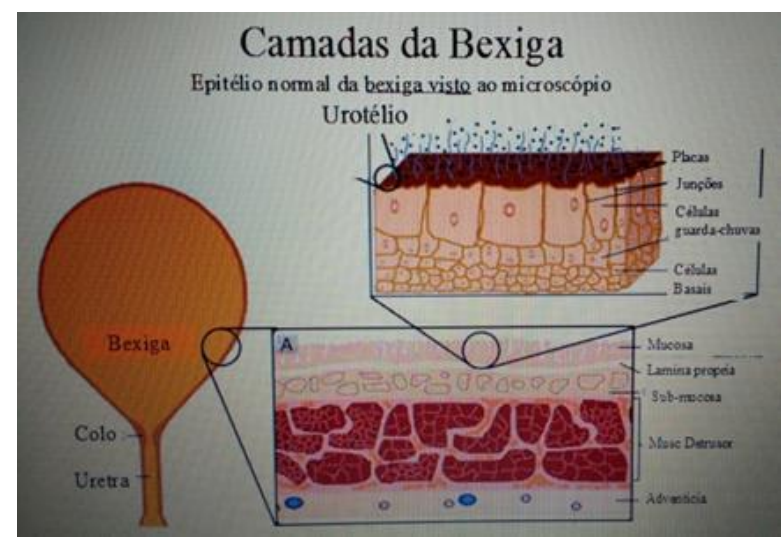

Figura 1. Ilustração de corte histológico da bexiga. Gatos com CIF possuem alterações na união das membranas uroteliais e junções estreitas das células guarda-chuvas (Rodrigues, 2017)

Foi demonstrado que o aumento da permeabilidade em gatos com CIF crônica está presente mesmo quando os animais não mostram sinais de inflamação ativa, resultando em infiltração de mastócitos, aumento do fator de crescimento nervoso (NGF) na urina e tecido (epitelial e muscular liso) e aumento no número de fibras sensoriais nervosas na bexiga (fibras $\mathrm{C}$ ) (Liu and Kuo, 2007, Micera et al., 2007, Chew et al., 2012b) (Figura 2). Somado a isso, a liberação aumentada de ATP a partir do urotélio pode levar a sensações dolorosas através da sensibilização dessas fibras (Burnstock, 2009, Kaan et al., 2010).

Níveis elevados de óxido nítrico (NO) têm sido relatados em gatos com CIF, sendo associados a alterações na integridade do urotélio (Birder et al., 2005). Interações simpatoneurais-epiteliais parecem desempenhar um papel importante na permeabilidade. Birder et al., (2002) mostraram que a aplicação de norepinefrina (NE) em tiras de bexiga urinária $(\mathrm{BU})$ induziu a liberação de óxido nítrico do epitélio da BU. Já a aplicação da capsaicina resultou na libertação de óxido nítrico tanto do epitélio como do tecido nervoso da BU. A NE circulante no organismo do gato com CIF, por sua vez, apresenta-se aumentada tanto em estados de repouso quanto excitatórios (Anjos, 2014). O que poderia explicar altos níveis contínuos de NE seriam eventos de stress, inflamação e dor igualmente contínuos, ativando o sistema nervoso simpático (SNS) e seus mediadores, tal como o fator liberador de corticotrofina (CRF) (Keay et al., 2014) e a enzima tirosina-hidroxilase (TH) (Sands et al., 2000).

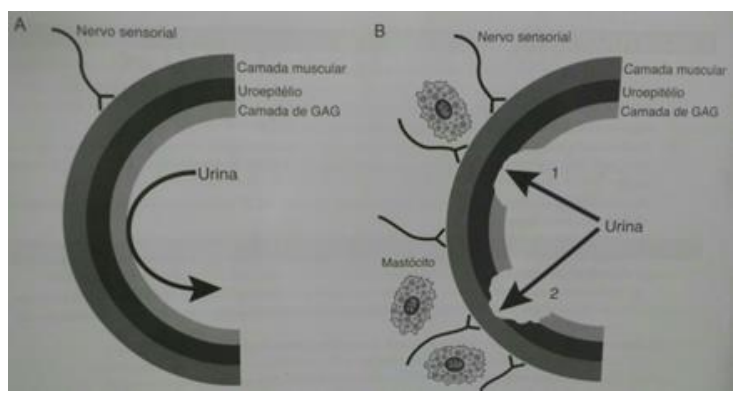

Figura 2. A: Ilustração da bexiga de gato normal. B: gato com CIF. As camadas teciduais podem ser danificadas em diferentes graus, contribuindo para aumento de permeabilidade, infiltração mastocitária, aumento de fibras sensoriais e inflamação neurogênica (Chew et al., 2012b).

A ativação contínua do SNS pode levar a uma dessensibilização funcional dos adrenoceptores alfa-2 centrais (Westropp et al., 2007). No tronco encefálico, particularmente a área do Locus Coeruleus (LC), os agonistas $\alpha-2$ inibem a liberação de NE, enquanto que na medula espinhal, inibem a transmissão da entrada nociceptiva ao cérebro (Stevens and Brenner, 1996). Com a dessensibilização desses receptores as concentrações plasmáticas de NE podem aumentar ainda mais. Além disso, pode ocorrer uma atrofia das glândulas adrenais, com consequente comprometimento do funcionamento do eixo HHA (Figura 3).

Em secções da glândula adrenal de gatos com CIF e gatos normais, Westropp et al. (2003) constataram redução significativa das áreas correspondentes às zonas fasciculada e reticulada corticais em comparação ao controle, bem como baixos níveis de cortisol após estimulação com altas doses de ACTH sintético. Mas a medula adrenal, que é responsável pela produção de catecolaminas, é ligeiramente maior em gatos com CIF comparada com gatos normais (Chew et al., $\underline{2012 b}$ ). A explicação mais sóbria identificada até 
o momento para esses achados é a ocorrência de eventos estressantes maternos que permitiram que os glicocorticóides da mãe atravessassem a placenta e inibissem a liberação de ACTH fetal (Buffington, 2009).

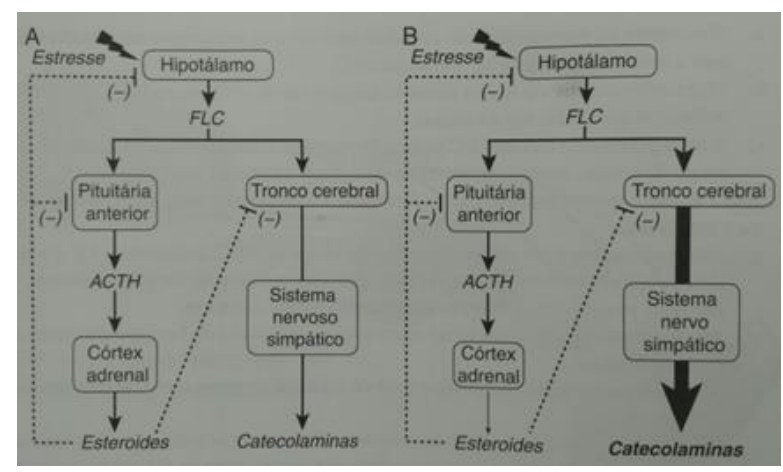

Figura 3. A: Resposta normal ao stress. B: Resposta anormal ao stress na CIF. Produção de corticosteroides é reduzida, assim como o feedback negativo efetuado pelos mesmos no SNC, resultando em superestimulação na produção de catecolaminas (Chew et al., 2012).

A sensibilização do sistema de resposta ao estresse (SRE) na vida fetal e a ativação repetida por eventos ambientais pode afetar adversamente uma variedade de órgãos com base na susceptibilidade familiar (Buffington, 2017), por modulações na expressão genética (Hunter and McEwen, 2013). Isso pode explicar o motivo pelo qual gatos com CIF possuam anormalidades em outros sistemas, além do Trato Urinário Inferior (TUI) (Stella et al., 2011), bem como a razão de muitas delas iniciarem antes mesmo dos STUI (Buffington, 2017).

\section{Epidemiologia}

Segundo Buffington (2017), a CIF apresenta prevalência de 55-73\% em relação aos gatos apresentados para avaliação de STUI, e incidência de 1,5-6 \% em relação a todos os gatos atendidos (Chew et al., 2012a). Maior predisposição para gatos jovens a meia idade (Crivellenti, 2015). A média de idade de gatos acometidos gira em torno de 1 a 10 anos, com picos de ocorrência entre 2 a 7 anos e não há predisposição racial (Chew et al., 2012a). Ocorre em ambos os sexos na maioria dos estudos (Willeberg, 1984, Buffington et al., 1997, Jones et al., 1997, Westropp, 2011) e embora possa ser obstrutiva ou não obstrutiva em sua apresentação, obstrução uretral é muito mais comum em gatos machos, sem diferença relatada entre machos inteiros e castrados (Hostutler et al., 2005).

Em estudo conduzido por Defauw et al. (2011), gatos com FIC tinham peso e escore de condição corporal significativamente maior; eram mais propensos a ser alojados em casas com múltiplos gatos, mais nervosos e temerosos, a se esconder de visitantes desconhecidos na casa e apresentavam menor ingestão de água, nível de atividade, comportamento de caça e menos acesso ao exterior do que os gatos controle. Chew et al. (2012) pontuam ainda que o uso de caixa de areia pequena para urinar e defecar, consumo de dietas consistindo em 75-100\% de alimentos secos, sedentarismo, interação estressante com os donos ou com o ambiente e mudanças recentes ou constantes na rotina podem atuar como fatores de risco para CIF.

Um erro muito comum dos tutores é aglomerar diversos gatos em um mesmo ambiente. Os gatos são animais relativamente solitários (Gittleman, 1989) e frequentemente escolhem uma densidade populacional de menos de 50 gatos por quilômetro quadrado $\left(\mathrm{km}^{2}\right)$. Embora os gatos machos $\mathrm{e}$ fêmeas de livre ocupação ocupem áreas domésticas sobrepostas de cerca de 100 metros de diâmetro, muitas vezes evitam encontrar-se um com o outro, mantendo um cronograma (Buffington, 2011). Em um estudo de família com dois gatos, cerca de $50 \%$ do tempo foi gasto fora da vista um do outro, mesmo que eles estivessem, muitas vezes, dentro de 1 a 3 metros um do outro (Barry and Crowell, 1999).

\section{Sinais clínicos}

Os sinais mais comuns são micção em locais impróprios (periúria); micção dolorosa ou difícil (disúria); esforço ao urinar devido à espasmos vesicais e uretrais (estrangúria); frequência excessiva, porém em pequenos volumes (polaciúria/polaquiúria); ausência de urina (anúria); sangue na urina (hematúria); vocalização; redução do apetite (hiporexia); ausência de apetite (anorexia); êmese; diarreia; isolamento; apatia; lambedura excessiva da região perineal e abdome caudal, bem como arrancamento de pelos em flancos e base da cauda. Esses sinais podem ser intermitentes e apresentar remição e recorrência com ou sem tratamento (Chew et al., 2012a, Anjos, 2014, Crivellenti, 2015, Dibartola, 2015). Podem, ainda, ser agudos ou crônicos e avaliação detalhada deve ser feita para diferencia-los, pois, sinais crônicos demandam avaliação diagnóstica e plano de tratamento mais extensivos (Chew et al., 2012a). Os STUI podem preceder a forma obstrutiva (Tabar Rodrígues and Planellas Bachs, 2012), sendo muito oportuno enfatizar a colaboração do 
tutor com o intuito de minimizar o risco de obstrução ou mesmo evitar sua ocorrência, gastos com internação e procedimentos mais invasivos e radicais, como a uretrostomia perineal.

\section{Anamnese}

Devido implicação do estresse como provável desencadeante e/ou perpetuante das alterações orgânicas e, consequentemente, dos sinais clínicos, a anamnese deve principalmente se voltar para averiguação do histórico desses sinais, de eventos pregressos e dos recursos ambientais. Isso é feito comumente com aplicação de questionários. $\mathrm{O}$ tutor deve responder os questionários para todos os gatos da casa e, posteriormente, o clínico deve identificar as questões que possam estar contribuindo para os sinais clínicos, implementando as recomendações terapêuticas para cada situação (Dibartola, 2015). Segundo Chew et al., (2012a), a periúria é a queixa mais comumente relatada pelos tutores sendo, em alguns casos, o único sinal. Outros sinais muitas vezes estão presentes, mas, na maioria das vezes, o tutor não percebe (Tabar Rodrígues and Planellas Bachs, 2012). Caso o tutor relate que o animal esteja em anúria, deve-se antecipar o exame físico com a palpação da bexiga e, constatando-se a obstrução, iniciar as manobras de desobstrução, pois trata-se de uma emergência, uma vez que o paciente pode vir a óbito por injúria renal aguda (Anjos, 2014). Enquanto o clínico se ocupa com o procedimento, o tutor pode adiantar o preenchimento do questionário.

\section{Exame físico}

Durante as crises de CIF não obstrutiva, à palpação, a bexiga estará diminuída devido à micção irritativa e o restante do exame físico geralmente é normal (Chew et al., 2012a). Em casos obstrutivos, além da bexiga extremamente repleta e facilmente palpável, podem ser evidenciadas desidratação, taquipnéia, arritmia, pulso periférico fraco, pênis congesto estendendose do prepúcio e hipo/hipertermia (Reche and Camozzi, 2015).

A maioria dos gatos que apresentam OU está relativamente estável, embora $12 \%$ apresentem quadro clínico mais severo (letargia, debilidade), bem como alterações eletrolíticas e ácido-básicas importantes que serão vistas mais adiante (Tabar Rodrígues and Planellas Bachs, 2012). Segundo Chew et al. (2012b), temperatura retal entre 35$35,8^{\circ} \mathrm{C}$ e frequência cardíaca $<120 \mathrm{bpm}$ é um preditor acurado para hipercalemia intensa $(>8,0$ $\mathrm{mEq} / \mathrm{L}$ ) em 98 a $100 \%$ dos casos.

Após compressão da bexiga, pode-se notar fluxo urinário de diâmetro reduzido, ou caso seja parcial. Em qualquer caso, é importante tomar cuidado com a pressão exercida sobre a bexiga, em virtude da dor e provável fragilidade tecidual, podendo levar à sua ruptura (Anjos, 2014). Um tampão pode inclusive ser visualizado protruindo da ponta do pênis e/ou pode haver material aderido à pelagem perineal (Chew et al., 2012a).

\section{Exames complementares}

Como cerca de 2/3 dos gatos com STUI apresentam CIF e em aproximadamente $85 \%$ destes gatos os sinais clínicos resolvem-se em 2-3 dias sem tratamento, é discutível se algum diagnóstico deve ser realizado para um gato jovem com seu primeiro episódio de STUI (Westropp, 2011). Além do número de episódios, a gravidade dos sinais clínicos e quanto o tutor está disposto a investir influenciam na escolha dos exames mais apropriados para cada caso em particular (Dibartola, 2015). O diagnóstico de CIF baseia-se na exclusão de outras causas de doença do trato urinário inferior (DTUIF) (Crivellenti, 2015), como urolitíase (10-20\%), distúrbios anatômicos (10\%), distúrbio comportamental (10\%), ITU (< $2 \%)$ e Neoplasias $(<1 \%)$ (Chew et al., 2012a).

Os exames que poderiam ser solicitados são:

\section{Urinálise}

As amostras de urina podem ser obtidas por diferentes métodos: micção espontânea, cateterização ou cistocentese, sendo que para avaliação microbiológica, preconiza-se a cistocentese (Tabar Rodrígues and Planellas Bachs, 2012). Nos gatos obstruídos pode-se aproveitar o momento da cistocentese descompressiva para colheita de amostra e/ou enquanto o gato estiver cateterizado. Embora a maioria dos gatos com CIF não apresente infecção do trato urinário (ITU), uma urinálises completa deve ser realizada pelo menos uma vez naqueles com STUI crônicos (Buffington, 2017). As ITU ocorrem mais frequentemente em gatos que passaram por uretrostomia perineal, cateterizações repetidas, ou que estejam acometidos por doenças concomitantes, tais como diabetes mellitus, doença renal crônica e/ou hipertiroidismo (MayerRoenne et al., 2007). 
As alterações na urinálise não são específicas nem sensíveis para CIF (Chew et al., 2012a). Observa-se, em sua maioria, sedimento ativo com hematúria, proteinúria, cristalúria e piúria (Anjos, 2014). Eritrócitos e proteínas podem entrar na amostra devido à cistocentese, dessa forma, a importância da hematúria pode ser duvidosa em amostras colhidas por esse método (Chew et al., 2012a).

A densidade urinária (DU) muitas vezes é elevada. Caso a urina seja isostenúrica, devem-se considerar distúrbios poliúricos subjacentes (Westropp, 2011). DU extremamente alta (ex: 1,060-1080) pode aumentar o risco de perpetuar a CIF se o tratamento para reduzi-la não for iniciado (Chew et al., 2012b).

\section{Hemograma e Perfil sérico}

Hemograma e bioquímica sérica são geralmente normais em casos não obstrutivos e alterados nos casos obstrutivos e/ou associados à enfermidades concomitantes (Tabar Rodrígues and Planellas Bachs, 2012). No caso de obstrução uretral, é importante avaliar glicemia, hemogasometria e eletrólitos (ex: cálcio iônico, fósforo potássio), ureia, creatinina

(Reche and Camozzi, 2015). A magnitude das alterações varia dependendo da duração e extensão (parcial ou completa) da obstrução (Chew et al., 2012a). A retenção de fósforo secundária a obstrução uretral induz hipocalcemia (por ligação do fósforo ao cálcio ionizado), acentuando as alterações cardíacas causadas pela hipercalemia. Todo gato bradicardico deve ser considerado hipercalêmico, porém nem todo hipercalêmico terá bradicardia (Anjos, 2014).

\section{Exames de imagem}

Existem diferentes técnicas para avaliar a bexiga e uretra, tais como radiografias simples e contrastadas, ultrassonografia e uroendoscopia (Tabar Rodrígues and Planellas Bachs, 2012). Radiografias abdominais simples são particularmente úteis em gatos com OU para excluir a presença de cálculos radiopacos na bexiga e uretra (Figura 4) (Chew et al., 2012a), mas só detectam urólitos radiopacos com mais de 2-3 mm de diâmetro. Já para urólitos radiolucentes ou menores que isso, são necessários exames contrastados ou ultrassonográficos (Tabar Rodrígues and Planellas Bachs, 2012), assim como para avaliar a presença de massas, divertículo vesicouracal, coágulos de sangue e estenoses (Figura 5) (Anjos, 2014; Crivellenti, 2015), mas a ultrassom não serve para avaliar a uretra (Buffington, 2017).
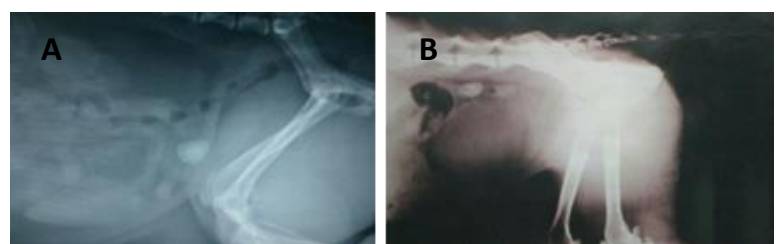

Figura 4. A: Urólito radiopaco em bexiga. B: Urólitos radiopacos na uretra (Labato, 2017, Tabar Rodrígues and Planellas Bachs, 2012).
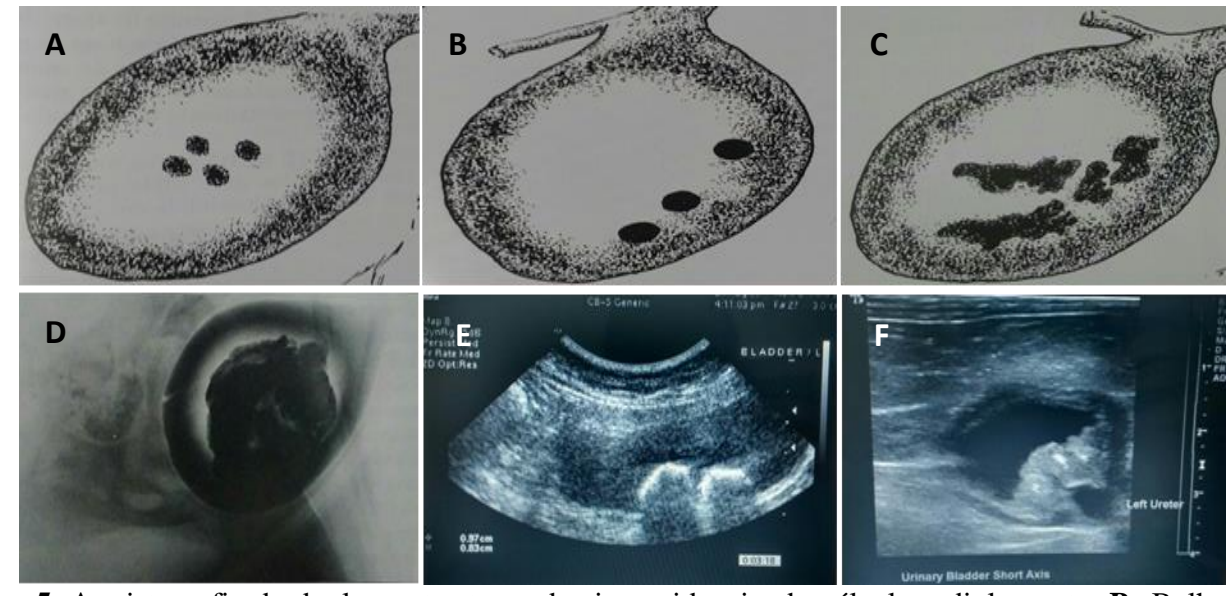

Figura 5. A: cistografia de duplo contraste em bexiga evidenciando cálculo radioluscente; B: Bolhas de ar (artefato); C: coágulos; D: pólipo; E: Ultrassonografia em bexiga constatando urólito; F: Carcionoma de

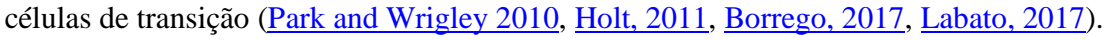

A uroendoscopia permite detectar as alterações que não foram evidenciadas pela ultrassonografia e radiografia (Reche and Camozzi, 2015), além de visualização de erosões e hemorragias na uretra
(Chew et al., 2012a); úlceras de Hunner, aumento da vascularização e hemorragias petequiais submucosas (glomerulações) na bexiga (Figura 6) (Tabar Rodrígues and Planellas Bachs, 2012). 

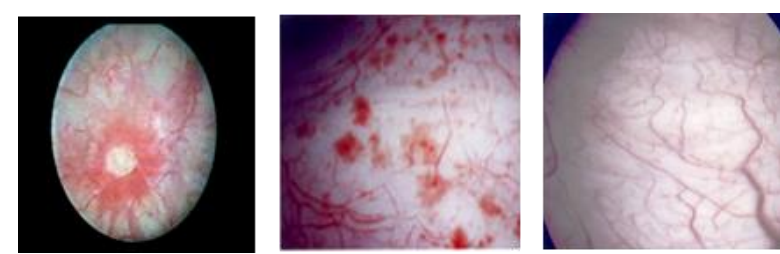

Figura 6. Da esquerda para a direita: Úlcera de Hunner evidenciada por cistoscopia; glomerulações; bexiga normal (Persu et al., 2010; Gibbin, 2010)).

Eletrocardiogramas são úteis em casos obstrutivos, principalmente na presença de hipercalemia. As alterações comumente encontradas são: bradicardia por distúrbios de condução supraventricular, redução de amplitude ou ausência de ondas P, complexos QRS mais largos, ondas $\mathrm{T}$ mais altas, intervalos QT mais curtos e depressões dos segmentos ST (Anjos, 2014).

\section{Tratamento}

\section{Gatos não obstruídos}

Visando a perspectiva de que a CIF represente um problema que afeta a bexiga em vez de um problema da bexiga, e que o SRE seja sensibilizado nos animais afetados, as abordagens que visam reduzir a ativação desse sistema consistem atualmente a principal forma de tratamento (Buffington, 2017). Essas abordagens consistem, em geral, na Modificação Multimodal Ambiental (MoMA) com base nos achados da anamnese, e controle farmacológico da dor e ansiedade em alguns casos (Westropp, 2011). Seja qual for à abordagem terapêutica, não há cura completa e o objetivo é aumentar o intervalo entre as crises e diminuir a gravidade dos sinais clínicos (Crivellenti, 2015).

\section{MoMA}

\section{Alimento e Água}

Os gatos preferem comer individualmente em locais silenciosos onde não sejam ameaçados ou assustados por outros animais, movimentos repentinos, duto de ar ou aparelho que possa começar a funcionar inesperadamente enquanto o gato está comendo (Buffington, 2011). Alimentos enlatados (úmidos) diminuem significativamente os sinais de CIF, pois diminui a densidade urinária e, consequentemente, a concentração de potenciais toxinas na bexiga (Forrester and Roudebush, 2007). Naqueles pacientes sem Doença Renal Crônica (DRC) e hipertensão, pode-se aumentar gradualmente o consumo de sal, até que a densidade urinária atinja 1,030 ou menos
(Chew et al., 2012a). A mudança alimentar muitas vezes não é fácil e deve ser feita de forma gradual, oferecendo o alimento novo em outro recipiente ao lado do alimento antigo. Assim que o gato comer, deve ser retirado diariamente $25 \%$ do alimento antigo, até ingerir somente a nova dieta (Westropp, 2011).

O comportamento de alimentação felina natural inclui atividades predatórias, tais como perseguição e ataque. Estes podem ser simulados escondendo pequenas quantidades de alimentos em torno da casa ou colocando alimentos em um dispositivo de alimentação a partir do qual o gato tem que extrair peças individuais ou move-las para liberar os pedaços de alimentos (Buffington, 2017). Alguns gatos preferem ingerir água corrente (ex: torneiras, fontes) e a distribuição de várias vasilhas de água limpa e fresca pode também aumentar a ingestão da mesma (Tabar Rodrígues and Planellas Bachs, 2012). As vasilhas devem ser rasas e de boca larga para o gato não tocar as vibrissas (órgãos táteis sensoriais) na vasilha e não perderem o campo de visão em vasilhas profundas (Anjos, 2014).

\section{Espaço e contatos sociais}

Os gatos interagem com as estruturas físicas e outros animais, incluindo as pessoas, em seu ambiente. Esse deve incluir oportunidades de arranhar (horizontal e vertical), escalar, esconder e descansar (Buffington 2011). Gatos preferem monitorar seu entorno de lugares altos, tornando a escalada de objetos, passarelas, prateleiras e assentos, ideais (Chew et al., 2012a). Deve-se estimular atividades com brinquedos e evitar mudanças nos hábitos do animal, como viagens, mudanças físicas do ambiente, introdução abrupta de novos animais e superpopulação (Anjos, 2014).

\section{Bandeja sanitária}

Manter as bandejas sanitárias (BS) sempre limpas e secas, distantes da água e do alimento e, assim como para as vasilhas de água e comida, deve-se evitar coloca-las em lugares barulhentos ou excessivamente expostos (Crivellenti, 2015). As BS devem ser fornecidas em vários ambientes que proporcionem rota de fuga para o gato, principalmente aquelas com múltiplos gatos (Buffington, 2011). Deve-se seguir a regra do "1 mais 1", ou seja, uma BS para cada gato ou grupo de gatos mais uma caixa adicional (Chew et al., 2012a).

O tamanho da BS, bem como se é aberta ou fechada pode interferir na sua utilização, sendo 
oportuno deixar o gato escolher (Herron, 2010). O tipo de areia, igualmente, deve ser introduzido de acordo com a preferência do gato (Tabar Rodrígues and Planellas Bachs, 2012). Alguns ao invés da areia adaptam-se melhor ao uso de papel picado, jornal, tapete higiênico ou papel higiênico (Anjos, 2014).

\section{Terapia hormonal}

Embora não haja efeito estatisticamente comprovado em estudo, a utilização de feromônio facial felino (Feliway) apresentou uma tendência positiva, com menos crises de cistite e de traços comportamentais negativos, podendo ser útil em alguns gatos com CIF (Gunn-Moore and Cameron, 2004). Feromônios são ácidos graxos que parecem transmitir informações altamente específicas entre animais da mesma espécie (Westropp, 2011). Os mecanismos exatos de ação são desconhecidos, mas induzem mudanças tanto no sistema límbico como no hipotálamo, alterando o estado emocional do animal (Pageat and Gaultier, 2003). Feliway foi desenvolvido para reduzir a ansiedade e pode ser útil em conjunto com enriquecimento ambiental e outros tratamentos para FIC (Tabar Rodrígues and Planellas Bachs, 2012).

\section{Outros tratamentos}

Analgesia pode ser realizada em casos agudos ou crônicos agudizados. Utiliza-se, em geral por 3-4 dias, buprenorfina $(10-30 \mu \mathrm{g} / \mathrm{kg} \quad \mathrm{VO}$ TID/BID), butorfanol (0,4 mg/kg VO TID), tramadol (1-2 $\mathrm{mg} / \mathrm{kg}$ VO BID), fentanil transdérmico $\quad(0,002-0,005 \quad \mathrm{mg} / \mathrm{h}) \quad$ (Tabar Rodrígues and Planellas Bachs, 2012, Anjos, 2014; Crivellenti, 2015). Segundo Buffington (2017) não há estudos que comprovem a segurança e eficácia de antiinflamatórios não esteroidais (AINES) para CIF e, em humanos, AINES não tem sido eficazes no controle da dor da cistite intersticial (Chew et al., 2012a).

Na CIF crônica e grave, quando a MoMA e tratamento hormonal não surtirem efeito, ou quando houver uma fonte importante de estresse que não possa ser eliminada, amitriptilina e clomipramina, dois antidepressivos tricíclicos podem ser utilizados (Chew et al., 1998). A amitriptilina possui propriedades anticolinérgicas (aumenta capacidade de retenção da bexiga), antihistamínicas (estabiliza mastócitos infiltrados na bexiga), analgésicas e antiinflamatórias (diminui atividade dos nervos da bexiga e liberação de $\mathrm{NE}$ no cérebro) (Anjos, 2014; Chew et al., 2012a).
Sugere-se a dose de $5-10 \mathrm{mg} /$ gato VO SID à noite, entretanto, recomenda-se iniciar com $1 \mathrm{mg} / \mathrm{kg}$, sendo a dosagem ajustada até produzir um leve efeito calmante (Anjos, 2014).

A clomipramina pode ser utilizada na dose de $0,25-0,5 \mathrm{mg} / \mathrm{kg}$ VO SID, tendo demonstrado menores efeitos adversos que a amitriptilina (Crivellenti, 2015). Esses efeitos podem ser letargia, sedação e retenção urinária (Dibartola, 2015). Antidepressivos tricíclicos não são eficazes no curto prazo, e caso não sejam observados resultados favoráveis em até 4 meses, o medicamento deve ser gradativamente reduzido até ser suspenso (Reche and Camozzi, 2015).

\section{Gatos obstruídos}

A gravidade dos sinais clínicos da uremia, os achados do eletrocardiograma (ECG) e a magnitude da distensão vesical ditam o quão rapidamente e em que sequência (Figuras 7 e 8) o tratamento deve ser instituído (Chew et al., 2012a). O objetivo principal é restaurar a patência uretral e corrigir as alterações sistêmicas pela reposição de fluidos e eletrólitos (Anjos, 2014).

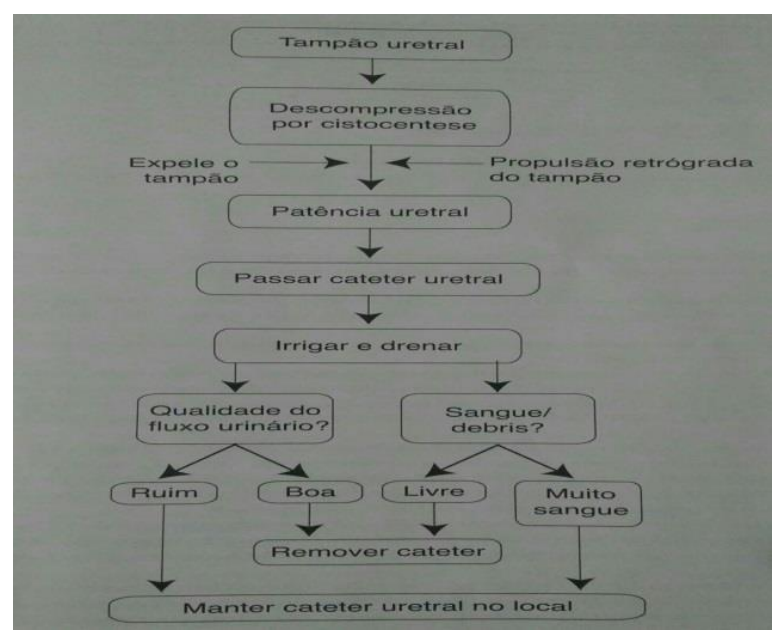

Figura 7. Algoritmo para obstrução urinária em animais estáveis (Chew et al., 2012b).

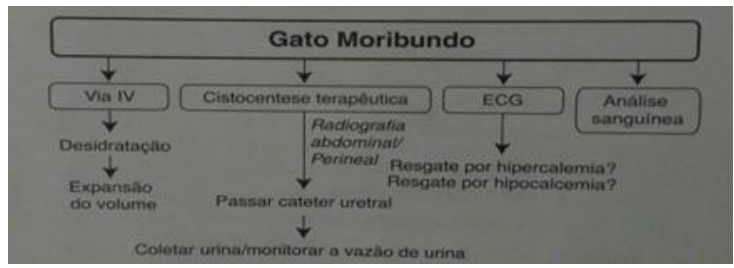

Figura 8. Algoritmo para obstrução urinária em gatos instáveis com obstrução uretral avançada (Chew et al., 2012a).

A cistocentese é feita, geralmente, com uma agulha $22 \mathrm{G}$ (Figura 9) que pode ser conectada a 
um extensor e válvula de três vias (Dibartola, 2015). Analgesia deve ser providenciada e os opióides são os mais indicados (Anjos, 2014). A reposição de fluido deve ser baseada no grau de desidratação (Tabar Rodrígues and Planellas Bachs, 2012).
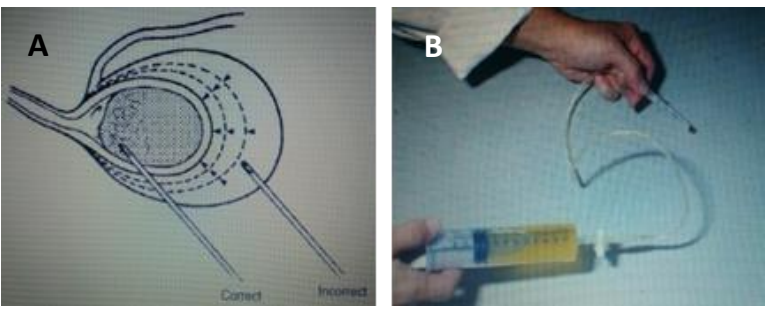

Figura 9. A: A agulha deve ser inserida na face ventral ou ventrolateral, no sentido craniocaudal até a junção do colo da bexiga com a uretra. A posição correta permite a remoção de um grande volume de urina e descompressão do lúmen sem necessidade de reinserção da agulha na bexiga. B: Material utilizado para cistocentese (Osborne et al., 2011).

Em caso de hipercalemia severa os animais não devem ser sedados ou anestesiados (Crivellenti, 2015). O tratamento pode incluir o gluconato de cálcio $(50-100 \mathrm{mg} / \mathrm{kg}$ IV durante 2-3 minutos, monitorando o ECG) para neutralizar o efeito da hipercalemia no coração ou medidas para diminuir a concentração de potássio sérico, como o bicarbonato (1-2 $\mathrm{mEq} / \mathrm{kg}$ IV) e infusão de insulina regular $(0,5 \mathrm{UI} / \mathrm{kg} \mathrm{IV})+4 \mathrm{~mL}$ de dextrose a $50 \%$ por UI de insulina administrada (Bartges, 2011).

Geralmente, após liberação da obstrução e restauração da função renal, a concentração sérica de potássio declina rapidamente podendo levar a uma hipocalemia. Observa-se também a correção da acidose metabólica, especialmente quando solução polieletrolítica cristaloide alcalinizante é utilizada (ex: Ringer Lactato) (Chew et al., 2012a).

Hipocalcemia ionizada pode ser tratada com gluconato de cálcio, caso necessário (Lee and Drobatz, 2003). Está presente, em sua maioria, em casos críticos, devendo-se intervir apenas nos animais que apresentem alterações cardiovasculares e rigidez muscular (Tabar Rodrígues and Planellas Bachs, 2012).

Com o animal estável, deve-se proceder com a anestesia. Diversos protocolos têm sido sugeridos, como por exemplo: cetamina $(5-10 \mathrm{mg} / \mathrm{kg}$ IV) associada ao diazepam $(0,2-0,5 \mathrm{mg} / \mathrm{kg}$ IV) ou midazolam $(0,2-0,5 \mathrm{mg} / \mathrm{kg} \mathrm{IV})$; butorfanol $(0,2$ $\mathrm{mg} / \mathrm{kg}$ IV) e diazepam $(0,2-0,5 \mathrm{mg} / \mathrm{kg}$ IV) ou midazolam $(0,2-0,5 \mathrm{mg} / \mathrm{kg}$ IV) e cetamina (2 $\mathrm{mg} / \mathrm{kg} \mathrm{IV}$ ), podendo-se repetir dose de butorfanol ou benzodiazepínicos, ou ainda bolus de propofol
(2-4 $\mathrm{mg} / \mathrm{kg}$ IV) em casos de cateterização prolongada; anestesia inalatória; epidural (5 $\mathrm{mg} / \mathrm{kg}$ de lidocaína associada ou não à morfina $(0,1 \mathrm{mg} / \mathrm{kg})$, diluída até o volume de $0,26 \mathrm{ml} / \mathrm{kg}$ (Reche and Camozzi, 2015; Tabar Rodrígues and Planellas Bachs, 2012).

Posicionar o gato em decúbito dorsal ou lateral, tricotomizar a região perineal, realizar antissepsia e manipular os materiais e a região com luvas estéreis (Dibartola, 2015). Para desobstrução pode-se utilizar cateter intravenoso $\mathrm{n}^{\circ} 20-22 \mathrm{sem}$ o estilete e promover jatos de baixa pressão com auxilio de seringa de $10 \mathrm{~mL}$ e solução fisiológica (Crivellenti, 2015). Após a desobstrução uretral, um cateter uretral macio Tomcat de 3,5 ou $5 \mathrm{Fr}$ (Figura 10) (Dibartola, 2015) deve ser introduzido para realizar lavagens na bexiga e, se for o caso, mantê-lo por 24 a 72 horas até que a urina se torne clara, a azotemia tenha se resolvido, a diurese normalizado e a inflamação e uretroespasmo retrocedidos.
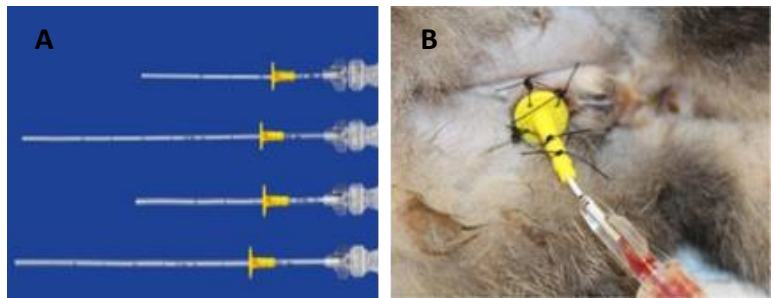

Figura 10. A: Cateteres Tomcat em diâmetros de 3,5 e 5 Fr com 15 e $25 \mathrm{~cm}$; B: Cateter suturado ao prepúcio (Milainternational.com).

Anestesia associada com a analgesia, juntamente com manipulação delicada e correta do cateter (Figura 11), torna a introdução mais segura, evitando ao máximo os traumas uretrais iatrogênicos que podem levar a extravasamento de urina para o tecido periuretral (Figura 12) e estenose (Anjos, 2014). Manter em circuito fechado e monitorar o débito urinário (Figura 13) (Chew et al., 2012a).

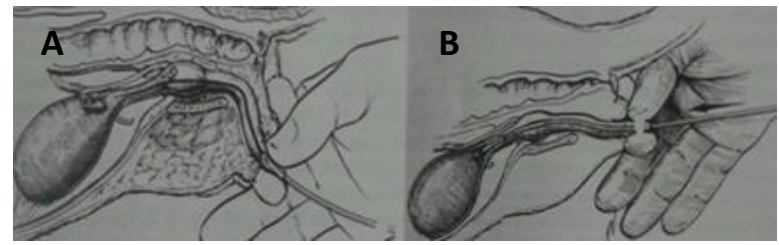

Figura 11. A: Introduzir cateter em direção oblíqua, no sentido ventro-dorsal; B: Quando o cateter estiver entre a uretra pós-prostática e uretra peniana deve-se deslocar o pênis caudo-dorsalmente para facilitar a introdução e minimizar risco de lesão uretral (Osborne and Finco, 1995, Anjos, 2014,). 
Durante o período que o gato permanece sondado e na semana seguinte após retirada da sonda, a administração de um antagonista dos receptores alfa 1 (prazosina $0,5 \mathrm{mg} /$ gato VO BID) ajuda a diminuir o espasmo da musculatura lisa uretral secundário ao cateter (Bartges, 2011). Para relaxar a musculatura esquelética uretral pode-se utilizar o Dantrolene (0,5 a $2 \mathrm{mg} / \mathrm{kg}$ VO TID-BID) (Anjos, 2014; Tabar Rodrígues and Planellas Bachs, 2012). AINES não são indicados devido ao quadro azotêmico, porém, em alguns casos, após resolução da azotemia, pode-se optar pelo uso de meloxicam $0,1 \mathrm{mg} / \mathrm{kg} \mathrm{SC}$ ou cetoprofeno $1 \mathrm{mg} / \mathrm{kg}$ VO, em uma única aplicação (Crivellenti, 2015). No mais, após a retirada do cateter, a conduta crônica é igual à CIF não obstrutiva (Dibartola, 2015).
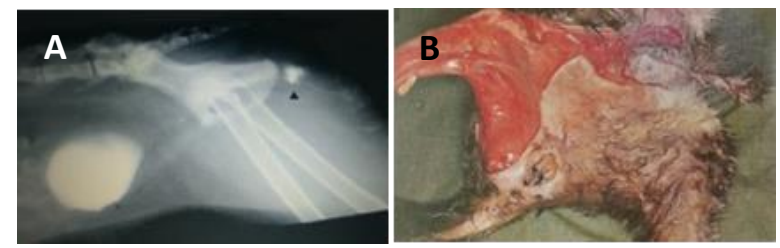

Figura 12. A: uretrocistograma contrastado retrógrado evidenciando extravasamento de meio de contraste da uretra após desobstrução uretral; B: perda de pele devido ao efeito da urina no espaço subcutâneo, após ruptura uretral (Bartges, 2011, Holt, 2011).

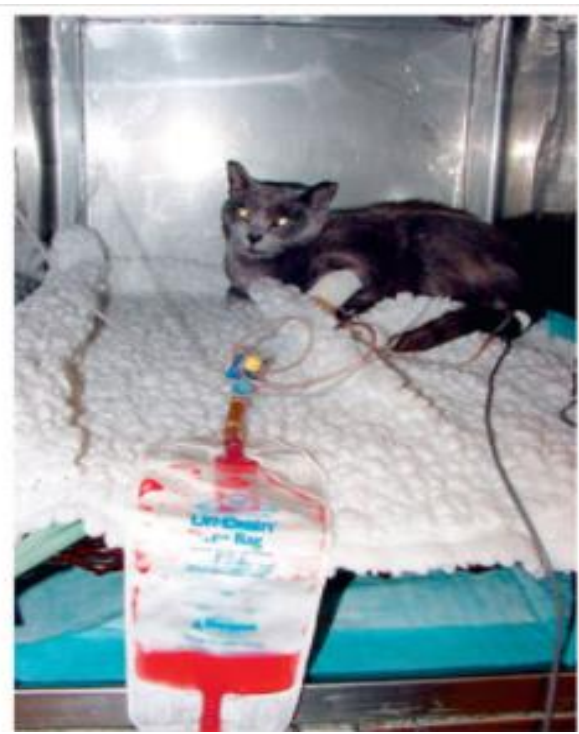

Figura 13. Circuito fechado para drenagem de urina, monitoração do débito e prevenção de ITU (Dibartola, 2015).

\section{Conclusão}

A CIF aparenta ser desencadeada por mecanismos que não estão relacionados propriamente à estrutura e funcionamento da bexiga, embora indiretamente possam afeta-los. As evidências apontam o estresse como um importante incitador e perpetuador das alterações comumente encontradas na bexiga, bem como da desregulação de mecanismos fisiológicos responsáveis pela modulação hormonal. Muito ainda precisa se investigar para melhor compreender a fisiopatologia da doença, para, dessa forma, prevenir a sua ocorrência e, caso ocorra, melhorar a eficácia do tratamento.

\section{Referências bibliográficas}

Anjos, T. M. 2014. Urologia em medicina felina. In: Santos, K. K. F. (ed.) Guia prático de nefrologia em cães e gatos. L. F. Livros, Rio de Janeiro, Brasil.

Barry, K. J. \& Crowell-Davis, S. L. 1999. Gender differences in the social behavior of the neutered indoor-only domestic cat. Applied Animal Behaviour Science, 64, 193-211.

Bartges, J. 2011. Urethral diseases. In: Bartges, J. \& Polzin, D. J. Nephrology and urology of small animals. Wiley-Blackwell, Chichester, West Sussex, ENG.

Birder, L. A., Lobo-Johnston, A., Buffington, C. A., Roppolo, J. R., De Groat, W. C. \& Kanai, A. J. 2005. Altered inducible nitric oxide synthase expression and nitric oxide production in the bladder of cats with feline interstitial cystitis. Journal of Urology, 173, 625-629.

Birder, L. A., Nakamura, Y., Kiss. S., Nealen, M. L., Barrick, S., Kanai, A. J., Wang, E., Ruiz, G., De Groat, W. C., Apodaca, Watkins, S. \& Caterina, M. J. 2002. Altered urinary bladder function in mice lacking the vanilloid receptor TRPV1. Nature Neuroscience, 5, 856-860.

Borrego, J. F. 2017. Urogenital and mammary gland tumors. In: Ettinger, S.J., Feldman, E.C. \& Côte, E. (eds.) Textbook of veterinary internal medicine. Elsevier, St. Louis, Missouri, USA.

Buffington, C. A. T. 2009. Developmental influences on medically unexplained symptoms. Psychotherapy Psychosomatics, 78, 139-144.

Buffington, C. A. T. 2011. Idiopathic vystitis in domestic cats - Beyond the Lower Urinary Tract. Journal of Veterinary Internal Medicine. 25, 784-796.

Buffington, C. A. T. 2017. Feline idiopathic cystitis. In: Ettinger, S. J., Feldman, E. C. \& Côte, E. (eds.) Textbook of veterinary internal medicine. Elsevier, St. Louis, Missouri, USA. 
Buffington, C. A. T., Blaisdell, J. L., Binns JR, S. P. \& Woodworth, B. E. 1996. Decreased urine glycosaminoglycan excretion in cats with interstitial cystitis. Journal of Urology, 155, 1801-1804.

Buffington, C. A. T., Chew, D. J., Kendall, M. S., Scrivani, P. V., Thompson, S. B., Blaisdell, J. L. \& Woodworth, B. E. 1997. Clinical evaluation of cats with nonobstructive urinary tract diseases. Journal of the American Veterinary Medical Association, 210, 46-50.

Buffington, C. A. T., Westropp, J. L. \& Chew, D. J. 2014. From FUS to Pandora syndrome: Where are we, how did we get here, and where to now?. Journal of Feline Medicine and Surgery, 16, 385-394.

Burnstock, G. Purinergic mechanosensory transduction and visceral pain. 2009. Molecular Pain, 5, 69.

Chew, D. J., Buffington, C. A., Kendall, M. S., Dibartola, S. P. \& Woodworth, B. E. 1998. Amitriptyline treatment for severe recurrent idiopathic cystitis in cats. Journal of the American Veterinary Medical Association, 213, 1282-1286.

Chew, D. J., Dibartola, S. P. \& Schenck, P. A. 2012a. Uropatia e nefropatia obstrutiva. In:___. (eds.) Urologia e nefrologia do cão de do gato. Saunders Elsevier, Rio de Janeiro, Brasil.

Chew, D. J.,Dibartola, S. P. \& Schenck, P. A. 2012b. Cistite intersticial ou idiopática não obstrutiva em gatos. In:____. (eds.) Urologia e nefrologia do cão de do gato. Saunders Elsevier, Rio de Janeiro, Brasil.

Crivellenti, L. Z. 2015. Nefrologia e urologia. In: Crivellenti, L. Z \& Crivellenti, S. B. (eds.) Casos de rotina em medicina veterinária de pequenos animais. Medvet, São Paulo, Brasil

Defauw, P. A., Van De Maele, I., Duchateau, G., Polis, I. E., Saunders, J. H. \& Daminet, S. 2011. Risk factors and clinical presentation of cats with feline idiopathic cystitis. Journal of Feline Medicine and Surgery, 13, 967-975.

Dibartola, S. P. 2015. Cistite idiopática obstrutiva e não obstrutiva. In: Nelson, R. W. \& Couto, C. G. (eds.) Medicina interna de pequenos animais. Mosby Elsevier, Rio de Janeiro, Brasil.

Forrester, S. D. \& Roudebush, P. 2007. Evidencebased management of feline lower urinary tract disease. Veterinary Clinics of North America: Small Animal Practice, 37, 533-558.

Gibbin, M. 2010. Interstitial cystitis/painful bladder syndrome. Disponível em: < http://flipper.diff.org/apprulesitems/items/232 5>.

Gittleman, J. L. 1989. Carnivore group living: comparative trends. In:__ (ed.). Carnivore behavior, ecology, and evolution. Cornell University Press, Ithaca, NY, USA.

Gunn-Moore, D. A. \& Cameron, M. E. A. 2004. Pilot study using synthetic feline facial pheromone for the management of feline idiopathic cystitis. Journal of Feline Medicine and Surgery, 6, 133-138.

Hauser, P. J., Dozmorov, M. G., Bane, B. L., Slobodov, G., Culkin, D. J. \& Hurst, R. E. 2008. Abnormal expression of differentiation related proteins and proteoglycan core proteins in the urotheliumof patients with interstitial cystitis. The Journal of Urology, 179, 764769.

Herron, M. E. 2010. Advances in understanding and treatment of feline inappropriate elimination. Topics in Companion Animal Medicine, 25, 195-202.

Holt, P. E. 2011. Disúria não prostática. In:___ (ed.) Urologia em cães e gatos. Revinter, Rio de Janeiro, Brasil.

Hostutler, R. A., Chew, D. J. \& Dibartola, S. P. 2005. Recent concepts in feline lower urinary tract disease. Veterinary Clinics of North America: Small Animal Practice, 35, 147-170.

Hunter, R. G. \& McEwen, B. S. 2013. Stress and anxiety across the lifespan: structural plasticity and epigenetic regulation. Epigenomics, 177194.

Jones, B. R., Sanson, R. L. \& Morris, R. S. 1997. Elucidating the risk factors of feline urologic syndrome. New Zeland Veterinary Journal, 45, 100-108.

Kaan, T. K., Yip, P. K., Grist, J., Cefalu, J. S., Nunn, P. A., Ford, A. P., Zhong, Y. \& McMahon, S. B. 2010. Endogenous purinergic control of bladder activity via presynaptic $\mathrm{P} 2 \mathrm{X} 3$ and $\mathrm{P} 2 \mathrm{X} 2 / 3$ receptors in the spinal cord. Journal of Neuroscience, 30, 4503-4507.

Keay, K. S., Birder, L. A. \& Chai, T. C. 2014. Evidence for bladder urothelial pathophysiology in functional bladder disorders. Biomed Research International, 2014, 15. 
Labato, M. A. 2017. Lower Urinary Tract Urolithiasis-Feline. In: Ettinger, S.J., Feldman, E.C. \& Côte, E. (eds.) Textbook of veterinary internal medicine. Elsevier, St. Louis, Missouri, USA.

Lavelle, J. P., Meyers, S. A., Ruiz, W. G., Buffington, C. A., Zeidel, M. L. \& Apodaca, L. 2000. Urothelial pathophysiological changes in feline interstitial cystitis: a human model. American Journal of Physiology - Renal Physiology, 278, F540-553.

Lee, J. A. \& Drobatz, K. J. 2003. Characterization of the clinical characteristics, electrolytes, acid-base, and renal parameters in male cats with urethral obstruction. Journal Veterinary Emergency and Critical Care, 13, 227-233.

Liu, H. T. \& Kuo H. C. Intravesical botulinum toxin A injections plus hydrodistension can reduce nerve growth fator production and control bladder pain in interstitial cystitis. 2007. Urology, 70, 463-468.

Mayer-Roenne, B., Goldstein, R. E. \& Erb, H. N. Urinary tract infections in cats with hyperthyroidism, diabetes mellitus and chronic kidney disease. 2007. Journal of Feline Medicine Surgery, 9, 124-132.

Micera, A., Lambiase, A. Stampachiacchiere, B., Bonini, S., Bonini, S. \& Levi-Schaffer, F. 2007. Nerve growth factor and tissue repair remodeling: trkANGFR and p75NTR, two receptors one fate. Cytokine \& Growth Factor Reviews, 18, 245-256.

Nunes, M. B. S. F. 2015. Cistite idiopática felina. Dissertação (Mestrado) - Universidade de Évora, Escola de Ciência e Tecnologia.

Osborne, C. A., Lulich, J. P., Polzin, D. J. 2011. Feline urethral obstruction. In: Bartges, J., Polzin, D. J. (eds.) Nephrology and urology of small animals. Wiley-Blackwell, Chichester, West Sussex, ENG.

Pageat, P. \& Gaultier, E. Current research in canine and feline pheromones. 2003. Veterinary Clinics of North America: Small Animal Practice, 33, 187-211.

Park, R. D. \& Wrigley, R. H. 2010. Bexiga urinária. In: Thrall, D. E. (ed.) Diagnóstico de radiologia veterinária. Saunders Elsevier, Rio de Janeiro, Brasil.

Pereira, D. A., Aguiar, J. A., Hagiwara, M, K. \& Michelacci, Y. M. 2004. Changes in cat urinary glycosaminoglycans with age and in feline urologic syndrome. Biochimica et Biophysica Acta, 1672, 1-11.

Persu, C., Cauni, V., Gutue, S., Blaj, I., Jinga, V. \& Geavlete, P. From interstitial cystitis to chronic pelvic pain. 2010. Journal of Medicine and Life, 3, 167-174.

Press, S. M., Moldwin, R., Kushner, L. et al. 1995. Decreased expression of GP-51 glycosaminoglycan in cats afflicted with feline interstitial cystitis. Journal of Urology, 153, 288A.

Reche, A. \& Camozzi, R. B. 2015. Doença do trato urinário inferior dos felinos | cistite intersticial. In: Jericó, M. M., Neto, J. P. A. \& Kogika, M. M. (eds.) Tratado de medicina interna de cães e gatos. Roca, Rio de Janeiro, Brasil.

Rodrigues, P. Síndrome da Bexiga Dolorosa Ou Cistite Intersticial. Disponível em <http://www.drpaulorodrigues.com.br/patolog $\mathrm{ia} /$ sindrome-da-bexiga-dolorosa-cistiteintersticial/>.

Sands, S. A., Strong, R., Corbitt, J. \& Morilak, D. A. 2000. Effects of acute restraint stress on tyrosine hydroxylase mRNA expression in locus coeruleus of Wister and Wistar-Kyoto rats. Molecular Brain Research, 75, 1-7.

Slobodov, G., Feloney, M., Gran, C., Kyker, K. D., Hurst, R. E. \& Culkin, D. J. 2004. Abnormal expression of molecular markers for bladder impermeability and differentiation in the urothelium of patients with interstitial cystitis. Journal of Urology, 171, 1554-1558.

Stella, J. L., Lord L. K. \& Buffington, C. A. Sickness behaviors in response to unusual external events in healthy cats and cats with feline interstitial cystitis. 2011. Journal of the American Veterinary Medical Association. $238,67-73$.

Stevens, C. W. \& Brenner, G. M. 1996. Spinal administration of adrenergic agents produces analgesia in amphibians. European Journal of Pharmacology, 316, 205-210.

Tabar Rodríguez, M. D., Planellas Bachs, M. 2012. Doença do trato urinário inferior felino. In: Cortadellas, O. (ed.) Manual de nefrologia e urologia clínica canina e felina. Medvet, São Paulo, Brasil.

Veranic, P. \& Jezernik, K. The response of junctional complexes to induced desquamation in mouse bladder urothelium. 2000. Biology of the Cell, 92, 105-113. 
Westropp, J. L. 2011. Feline idiopathic cystitis. In: Bartges, J., Polzin, D. J. (eds.) Nephrology and urology of small animals. Wiley-Blackwell, Chichester, West Sussex, ENG.

Westropp, J. L., Kass, P. H. \& Buffington, C. A. $\mathrm{T}$. In vivo evaluation of the alpha-2 adrenoceptors in cats with idiopathic cystitis. 2007. American Journal of Veterinary Research, 68, 203-207.

Westropp, J. L., Welk, K. A. \& Buffington, C. A. T. 2003. Small adrenal glands in cats with feline interstitial cystitis. Journal of Urology, 170, 2494-2497.
Willeberg, P. 1984. Epidemiology of naturally occurring feline urologic syndrome. Veterinary Clinics of North America Small Animal Practice, 14, 455- 469.

\section{Article History:}

Received 29 May 2017

Accepted 6 June 2017

Available online 7 August 2017

License information: This is an open-access article distributed under the terms of the Creative Commons Attribution License 4.0, which permits unrestricted use, distribution, and reproduction in any medium, provided the original work is properly cited. 